\title{
An Analytical Hierarchy Process of Delay causes in Highway Construction Projects in Iran
}

\author{
Soo-Yong Kim, Kiyanoosh Golchin Rad
}

\begin{abstract}
Recently, the highway construction projects in Iran have been confronted with delay, terminated, or postponed for several years. Although widespread studies have been investigated, regarding to delay issue in developed and developing countries, however, only few studies addressed in Iran. Due to the importance of delay issue and lack of sufficient studies regarding to this topic in Iran, this study aimed to first, discover the most significant causes of delay in highway construction projects, second; prioritize, and rank the critical factors, in order to highlight them for highway construction projects authorities. A verified questionnaire prepared and distributed among the experts in the construction projects of Iran. The valid collected data analyzed by Exploratory Factor Analysis (EFA) to uncover the underlying structure of variables and reduce the number of them. Moreover, Analytical Hierarchy Process (AHP), as one of the prevalent decisions making tools, applied to prioritize and rank the significant factors. The study results revealed that the "Design" and "Contractor" were manifested as the most critical criteria regarding to delay in highway construction projects in Iran. Besides, poor procurement of construction materials, delay in manufacturing materials and accidents during construction were discovered as the most significant factors causing delay. This study contributed first to identify and prioritize the most significant causes of delay in construction projects in Iran, as a developing country, because of lack of sufficient studies regarding to this topic. Additionally it highlights the causes of delay for any involving parties in Iran construction projects in order to eliminate delay.
\end{abstract} words)

Keywords - component, formatting, style, styling, insert (key

\section{Introduction}

Delay, as one of the most critical issues in construction projects, always has been considered in construction project management and academia as well. Hence, widespread studies have been conducted regarding to this topic. These studies could be generally divided to two perspectives; first, factors causing delay in construction projects; second, delay analysis. Moreover, the delay issue is depended on project type, size, scope and location Elinwa and Joshua (2001). Project delay can be defined by two descriptions; First description defined as "time overrun from the planned or contract schedule"

Soo-Yong Kim, Professor, Department of Civil Engineering

Pukyong National University

Republic of Korea

Kiyanoosh Golchin Rad, PhD Candidate, Department of Civil Engineering

Pukyong National University

Republic of Korea
(Harris \& McCaffer, 2013; Majid \& McCaffer, 1998; Mendelsohn, 1994; Riad, Arditi, \& Mohammadi, 1991; Yates, 1993; Yates \& Guhathakurta, 1993); The second described as "the time overrun beyond the date that critical activities have been delayed" (Householder \& Rutland, 1990; Rad, 1979; Trauner, 1990).

\section{Literature Review}

Most of the delay factors in construction projects are common; however, depending on type of projects and scopes, there are different causes. Hence, the widespread studies have been conducted, particularly in developed countries and some studies in developing countries and Middle East as well, regarding to this issue. These studies can be categorized to the factors affecting delay and the delay analysis.

Le-Hoai \& Lee applied a comparative study regarding to causes of time-overrun and cost overrun among several selected construction industries in Africa and Asia which achieved to seven factors: Slowness and Lack of constraint; Incompetence; Design; Market and Estimate; Financial capability; Government; and Worker (Le-Hoai, Dai Lee, \& Lee, 2008). Kim and Tuan (2016) investigated delay causes in hospital construction in Vietnam. They identified the most important factors as follow; contractor and owner's ability, contractor and consultant's ability, outside effects, designer's ability, and supervisors' ability. Park and Kwon (2011) considered influencing factors in infrastructure construction in South Korea. Six critical success factors were recognized namely: competitive contractor, pre-project planning, contract strategy, engineering enforcement, contract guarantee, lessons learned feedback.

\section{Data Analysis and Findings}

This study attempted to identify, rank, and prioritize delay causes in highway construction projects in Iran. The research methodology has been integrated by Exploratory Factor Analysis (EFA) and Analytical Hierarchy process (AHP).

\section{A. Exploratory Factor Analysis (EFA)}

Before analyzing and applying EFA, the Crobach's Alpha test has been done to determine the internal consistency of items in the survey to measure its reliability. The $\alpha$ is 0.800 which is $0.8 \leq \alpha<0.9$ and according to Field (2009), the reliability is "good" and it means that the test is $80 \%$ reliable. Then, the mean score of each factor computed. According to Majid and McCaffer (1997), the factors with more than 3.5 
mean indexes are classified in the "Extremely effective" rating group. Consequently, the factors with less than 3.5 score average mean index removed from the potential factors list. Therefore, the exploratory factor analysis conducted with fortyfive factors. EFA conducted using Principal Component's method with Varimax rotation to see if the observed variables loaded together as expected and meet the criteria of reliability and validity. Therefore, KMO and Bartlett's test applied to check that factor analysis is applicable or not. The KMO measure was 0.835 which should be higher than 0.6 and Bartlett's test was less than 0.05 and extremely significant. Therefore, the variables have a correlation and EFA is quite applicable.

\section{B. Analytical Hierarchy Process}

The eight components were determined through the EFA, which are namely: Owner, External, Design Government, Contractor, Material, Consultant, and labor. These components were then prioritized through the AHP by weighting their related factors. With respect to the identified factors, AHP procedure has been explained as follow; Initially the AHP goal set as same as the study objective, Prioritize and rank the critical factors causing delay in Highway construction projects in Iran. Hence, an AHP questionnaire based on the hierarchy structure and Saaty's nine-point scale was designed and distributed among the experts. Out of twenty-five distributed questionnaires, sixteen (four Professors from academia, and twelve experts in highway construction projects with more five years experiences) were replied and made the pairwise comparison. Geo mean index of sixteen responses was calculated by Excel to synthesize the judgments due to obtain a single judgment for the group according to Saaty (2008). The synthesized judgments analyzed by the Expert Choice software to find out the priority weights of each criterion over the criteria with respect to the goal of the study. Consistency Ratios (CR) measured for all criterion and sub-criteria have been checked whether they are less than 10 percentages or not. In this study, all CRs were less than 0.1 (ten percentages) within qualified limits (Table1).

Table1. Priority weights of Criteria and Sub-Criteria

\begin{tabular}{|c|c|}
\hline Priorities with respect to: & Priority weights \\
\hline \multicolumn{2}{|l|}{$\begin{array}{l}\text { Level 1: Goal: Delay Causes in Highway } \\
\text { Construction Projects }\end{array}$} \\
\hline Level 2: & \\
\hline CONTRACTOR & 0.23 \\
\hline DESIGN & 0.148 \\
\hline EXTERNAL & 0.137 \\
\hline OWNER & 0.126 \\
\hline GOVERNMENT & 0.105 \\
\hline MATERIAL & 0.103 \\
\hline CONSULTANT & 0.095 \\
\hline LABOR PRODUCTIVITY & 0.055 \\
\hline
\end{tabular}

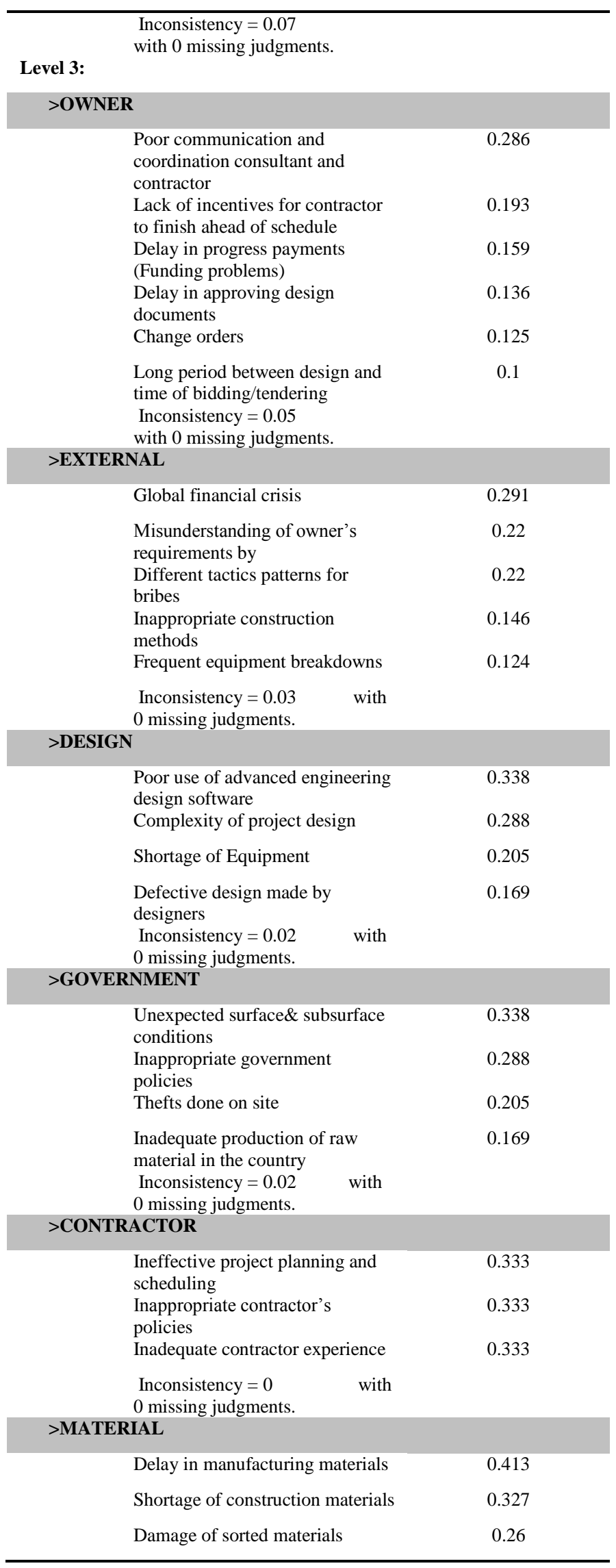


Proc. of the Sixth Intl. Conf. Advances in Civil, Structural and Mechanical Engineering - CSM 2018

Copyright (C) Institute of Research Engineers and Doctors, USA. All rights reserved.

ISBN: 978-1-63248-150-4 doi: 10.15224/978-1-63248-150-4-27

\begin{tabular}{|c|c|}
\hline $\begin{array}{c}\text { Inconsistency }=0.05 \\
\text { with } 0 \text { missing judgments. }\end{array}$ & \\
\hline \multicolumn{2}{|l|}{ >CONSULTANT } \\
\hline Accidents during construction & 0.338 \\
\hline $\begin{array}{l}\text { Delay in approving major } \\
\text { changes in scope of work }\end{array}$ & 0.288 \\
\hline $\begin{array}{l}\text { Lack of consultant experience in } \\
\text { construction projects }\end{array}$ & 0.205 \\
\hline Price fluctuations & 0.169 \\
\hline $\begin{array}{l}\text { Inconsistency }=0.02 \\
\text { with } 0 \text { missing judgments. }\end{array}$ & \\
\hline \multicolumn{2}{|l|}{ >LABOR PRODUCTIVITY } \\
\hline $\begin{array}{l}\text { Poor procurement of construction } \\
\text { materials }\end{array}$ & 0.667 \\
\hline Low productivity of labor & 0.333 \\
\hline $\begin{array}{l}\text { Inconsistency }=0 \\
0 \text { missing judgments. }\end{array}$ & \\
\hline
\end{tabular}

\section{Conclusion}

This study attempted; to investigate the factors affecting delay in highway construction projects in Iran; and it contributed to prioritize and rank critical factors, in order to highlight them for Iranian construction projects authorities. To this aim, an intensive literature review performed to identify the potential factors. The designated questionnaire modified trough the pilot study and distributed to the experts in construction projects in Iran. The valid selected data analyzed by EFA and AHP tools. Eventually, from the study results, it revealed that the "Design" and "Contractor" were the most prioritized criteria. Moreover, "poor procurement of construction materials", "delay in manufacturing materials" and "accidents during construction" were the most significant sub-criteria. Therefore, contractors and designers are highly recommended to consider these factors in order to eliminate delay and achieve the project success. The study results would be applicable in highway construction projects in Iran, and other Middle Eastern projects, based on the similarity of construction projects of that area.

\section{Acknowledgment}

This study was supported by a Research Grant of Pukyong National University (2017 year).

\section{References}

Elinwa, A. U., \& Joshua, M. (2001). Time-overrun factors in Nigerian construction industry. Journal of Construction Engineering and Management, 127(5), 419-425. doi: http://dx.doi.org/10.1061/(ASCE)0733-9364(2001)127:5(419)

Field, A. (2009). Discovering statistics using SPSS: Sage publications.

Harris, F., \& McCaffer, R. (2013). Modern construction management: John Wiley \& Sons.

Householder, J. L., \& Rutland, H. E. (1990). Who owns float? Journal of Construction Engineering and Management, 116(1), 130-133. doi: http://dx.doi.org/10.1061/(ASCE)0733-9364(1990)116:1(130)
Kim, S.-Y., \& Tuan, K. N. (2016). Delay factor analysis for hospital projects in Vietnam. KSCE journal of civil engineering, 20(2), 519-529. doi: http://dx.doi.org/10.1007/s12205-014-0679-8

Le-Hoai, L., Dai Lee, Y., \& Lee, J. Y. (2008). Delay and cost overruns in Vietnam large construction projects: A comparison with other selected countries. KSCE journal of civil engineering, 12(6), 367377. doi: http://dx.doi.org/10.1007/s12205-008-0367-7

Majid, M. A., \& McCaffer, R. (1997). Assessment of work performance of maintenance contractors in Saudi Arabia. Journal of management in engineering, 13(5), 91-91. doi: http://dx.doi.org/10.1061/(ASCE)0742-597X(1997)13:5(91)

Majid, M. A., \& McCaffer, R. (1998). Factors of non-excusable delays that influence contractors' performance. Journal of management in engineering, 14(3), 42-49. doi: http://dx.doi.org/10.1061/(ASCE)0742-597X(1998)14:3(42)

Mendelsohn, R. (1994). Early-completion schedules: the promise and pitfalls. Journal of management in engineering, 10(1), 28-30. doi: http://dx.doi.org/10.1061/(ASCE)9742-597X(1994)10:1(28)

Park, H.-S., \& Kwon, S. (2011). Factor analysis of construction practices for infrastructure projects in Korea. KSCE journal of civil engineering, 15(3), 439-445. doi: http://dx.doi.org/10.1007/s12205-011-1064-5

Rad, P. F. (1979). Delays in construction of nuclear power plants. Journal of the Energy Division, 105(1), 33-46.

Riad, N., Arditi, D., \& Mohammadi, J. (1991). A conceptual model for claim management in construction: An AI approach. Computers \& Structures, 40(1), 67-74. doi: http://dx.doi.org/10.1016/00457949(91)90458-X

Saaty, T. L. (2008). Decision making with the analytic hierarchy process. International journal of services sciences, 1(1), 83-98. doi: https://doi.org/10.1504/IJSSCI.2008.017590

Trauner, T. J. (1990). Construction delays: Documenting causes, winning claims, recovering costs: RS Means Company.

Yates, J. (1993). Construction decision support system for delay analysis. Journal of Construction Engineering and Management, 119(2), 226-244. doi: http://dx.doi.org/10.1061/(ASCE)07339364(1993)119:2(226)

Yates, J., \& Guhathakurta, S. (1993). International labor productivity. COST ENGINEERING-ANN ARBOR THEN MORGANTOWN-, 35, 15-15.

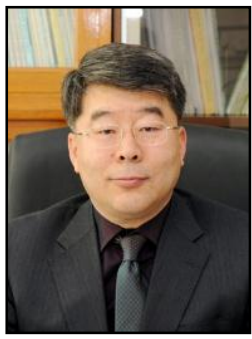

Prof. Soo Yong Kim is a full professor at the Department of Civil Engineering at Pukyong National University. He holds the PhD of Industrial Engineering from KAIST. He is the advisor of Construction Engineering and Management Lab. His major interests are Public Private Partnership (PPP) and Value Engineering (VE).

\begin{tabular}{|l|l|} 
& $\begin{array}{l}\text { Kiyanoosh Golchin Rad is a PhD candidate } \\
\text { of Construction Engineering and } \\
\text { Management at Pukyong National University. } \\
\text { He holds a B.sc in Civil Engineering and } \\
\text { M.sc in Construction Management from } \\
\text { University Technology of Malaysia (UTM). } \\
\text { His current research interest is construction } \\
\text { labor productivity. }\end{array}$ \\
\hline
\end{tabular}

